\title{
La divulgación como estrategia persuasiva en el discurso publicitario
}

Reporting as persuasive strategy in advertising discourse

\author{
LORENA CARMEN NEBOT CELADES
}

UNIVERSITAT JAUME I

Artículo recibido el / Article received: 21-10-2015

Artículo aceptado el / Article accepted: 15-10-2016

RESUMEN: El artículo trata sobre el uso de la divulgación en los textos publicitarios. A partir del análisis de las estrategias divulgativas más características de la publicidad, se observa su función en el proceso argumentativo de los anuncios que promocionan productos de origen científico o seudocientífico. Para ello, este artículo toma como referencia el esquema teórico propuesto por Cassany, López y Martí (2000), que clasifica el proceso divulgativo en tres actividades (retextualización, reconceptualización y redenominación). Este esquema permite observar la forma en que la publicidad desarrolla estrategias divulgativas con una clara orientación persuasiva, por un lado, mediante la apelación a reacciones humanas, como el miedo a no ser aceptado; por otro lado, a través de la conexión con los tópicos más habituales de la persuasión publicitaria, presentes en el imaginario colectivo del destinatario.

Palabras clave: tópicos publicitarios; estrategias de persuasión; proceso argumentativo; imaginario colectivo; divulgación científica.

ABSTRACT: This article is about the use of reporting in advertising texts. From the analysis of the most characteristic reporting strategies in advertising, it is seen its role in the advertisements' argumentative process, which promote products of scientific or pseudoscientific origin. For this purpose, this article takes as reference the Cassany, López and Martí's theoretical framework (2000), which classifies the reporting process into three activities (retexting, reconceptualization and renaming). This framework allows you to see how advertising develops reporting strategies with a clear persuasive orientation, on the one hand, by appealing to human reactions, as the fear of not being accepted; on the other hand, through the connection with the most common topics of persuasion advertising, which are present on the collective imagination of the receiver.

Keywords: advertising topics, estrategies of persuasion, argumentative process, collective imagination, scientifical reporting. 


\section{INTRODUCCIÓN}

El proceso de reelaboración y recontextualización de un texto especializado, con el objetivo de convertirlo en un discurso divulgativo al alcance de todos los públicos, se centra en la puesta en marcha de una serie de recursos y estrategias discursivas, que, en el caso de los mensajes publicitarios adquiere una serie de particularidades especiales, dado que persiguen un efecto perlocucionario para transformar al receptor del mensaje en consumidor.

A continuación, se llevará a cabo un análisis detallado de algunas de las principales estrategias divulgativas publicitarias, y, para ello, se tomará como modelo de referencia el esquema propuesto por Cassany, López y Martí (2000), que utiliza el término recontextualización para hacer referencia al proceso dirigido a la conversión de un texto especializado en un texto asequible para la mayoría de los miembros de una comunidad de habla. Este proceso discursivo, cuyo objetivo se centra en establecer una conexión entre el universo referencial del investigador científico y el imaginario colectivo de una comunidad de habla, según Cassany, López y Martí (2000), se desarrolla a través de tres tipos de actividades: retextualización, reconceptualización y redenominación.

\section{LA PUBLICIDAD COMO TEXTO DIVULGATIVO}

La recontextualización requiere la conexión entre el conocimiento científico y la vida cotidiana de la comunidad de habla a la que se dirige el mensaje, por lo que es necesario que el divulgador conozca las necesidades informativas del destinatario. En el caso de los géneros periodísticos, es importante destacar la popularización de la información económica, a causa de diversos factores, entre los que destaca la actual crisis económica, que ha tenido una gran influencia en la cotidianidad de los ciudadanos, lo que ha dado lugar a que los lectores potenciales de este tipo de información sean «cada vez más heterogéneos y con intereses muy diversos» (Vellón, 2014: 101).

Sin embargo, dado que, como afirman Fuentes y Alcaide (2007: 9), «cualquiera de nuestros discursos [...] responde a un propósito, una intención, una finalidad», el texto divulgativo es el resultado del punto de vista del autor y, por tanto, su finalidad no solo consiste en transmitir un conocimiento científico al gran público, sino que también se centra en ofrecer la opinión del divulgador, que, por ejemplo, en el caso de la información económica, puede hacer referencia a cuestiones como la vinculación entre los acontecimientos políticos y los mercados de valores. 
En el caso de los textos publicitarios, la orientación persuasiva de las estrategias de divulgación empleadas es mucho más explícita, precisamente debido a que la finalidad de este tipo de textos consiste en modificar la conducta del receptor para que adquiera el producto anunciado.

Así, los profesionales publicitarios aprovechan, por un lado, las reacciones humanas de origen antropológico, como por ejemplo, el miedo innato a no ser aceptado por el resto del grupo, y por otro lado, las creencias, los valores y los estereotipos sociales, instalados en el imaginario colectivo de la actual sociedad del consumo, tales como el culto al cuerpo, el anhelo de la eterna juventud y la preocupación por gozar de una buena salud, para desarrollar estrategias publicitarias centradas en lo que Díaz Rojo (2003: 219) denomina el higienismo y el sanismo consumista.

\section{RETEXTUALIZACIÓN: MULTIMODALIDAD, ECONOMÍA EXPRESIVA Y RECURSOS DIVULGATIVOS MACROTEXTUALES}

La retextualización consiste en la adecuación discursiva del texto de origen, con el objetivo de adaptarlo a las características del género que va a ser utilizado para su difusión. Para ello, se ponen en marcha diversos procesos discursivos, que, en el caso de los textos publicitarios, se resumen en los siguientes:

a) Adaptación a la multimodalidad publicitaria

Las estrategias discursivas que los profesionales publicitarios utilizan para elaborar este tipo de textos presentan diferencias en función del género publicitario en el que se inserte el mensaje, ya que, durante el proceso de retextualización, se lleva a cabo una adaptación de las estructuras textuales del discurso de origen a los sistemas semióticos que componen los mensajes publicitarios, cuyo uso varía según se trate de un anuncio escrito, audiovisual o digital.

En cuanto a los géneros publicitarios escritos, es necesario establecer una diferenciación entre aquellos anuncios en los que prima el código icónico, que persiguen un objetivo comunicativo eminentemente persuasivo, y aquellos en los que el componente verbal tiene un mayor peso, que tratan de convencer al lector, principalmente, por medio de los argumentos que desarrolla el texto verbal. 
Así, la preeminencia del componente icónico destaca por desarrollar estrategias divulgativas esencialmente persuasivas, que, en lugar de describir las propiedades del producto, o de destacar sus beneficios, se centran en la apelación a los sentimientos, las emociones, las creencias y los valores del receptor. Es el caso de la figura 1, que, mediante una metáfora visual de carácter hiperbólico, relaciona los vehículos de la marca BMW con la posesión de un estatus social alto.

En otras ocasiones, el componente icónico actúa como un elemento pedagógico, al establecer una conexión entre las nociones técnicas, que suelen relacionarse con determinados productos (farmacéuticos, nutricionales, tecnológicos, etc.), y la experiencia cognitiva del destinatario, su vida cotidiana. Un ejemplo de ello lo constituye la figura 2, que, a través de un componente icónico muy didáctico, transmite las propiedades hidratantes del producto anunciado, y, además, las presenta con un halo de rigor científico, mediante la incorporación de una probeta de laboratorio en la imagen.

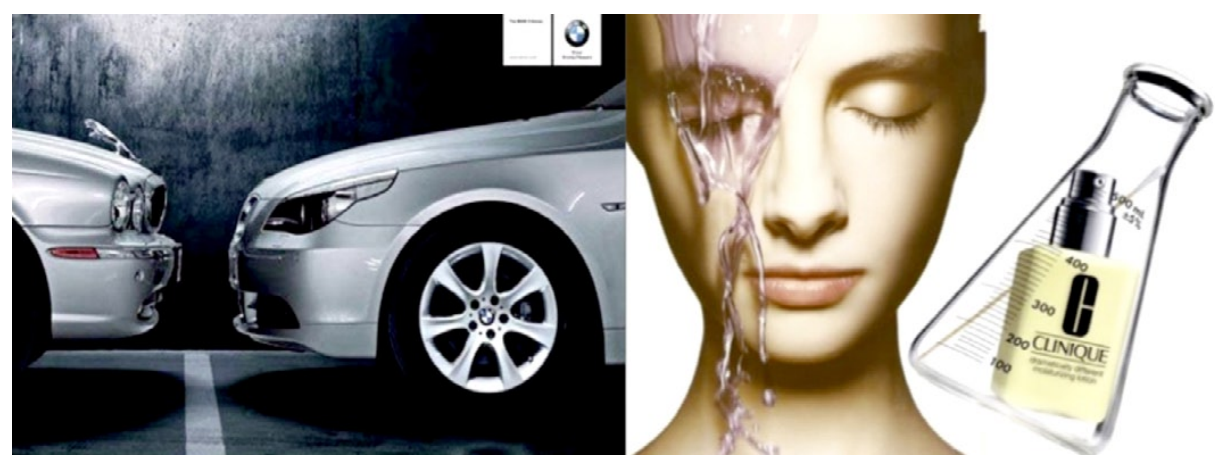

Figura 1

Figura 2

En segundo lugar, los anuncios que combinan el código icónico y el verbal, con el objetivo de persuadir al receptor, se caracterizan por la subordinación del texto verbal a la función persuasiva de la imagen. En este tipo de mensajes se produce un proceso de iconización verbal que es aprovechado, tanto para simplificar la interpretación del mensaje, como para conectar con el universo cognitivo del receptor y, de esta forma, despertar su interés hacia la compra del producto. En el caso de la Figura 3, el componente verbal se mimetiza con la vertiente icónica del mensaje, con el objetivo de explicar de forma visual el modo en que el producto mejora el aspecto de la piel, y, en consecuencia, de 
conectar con el anhelo de la eterna juventud, presente en el universo cognitivo del receptor.

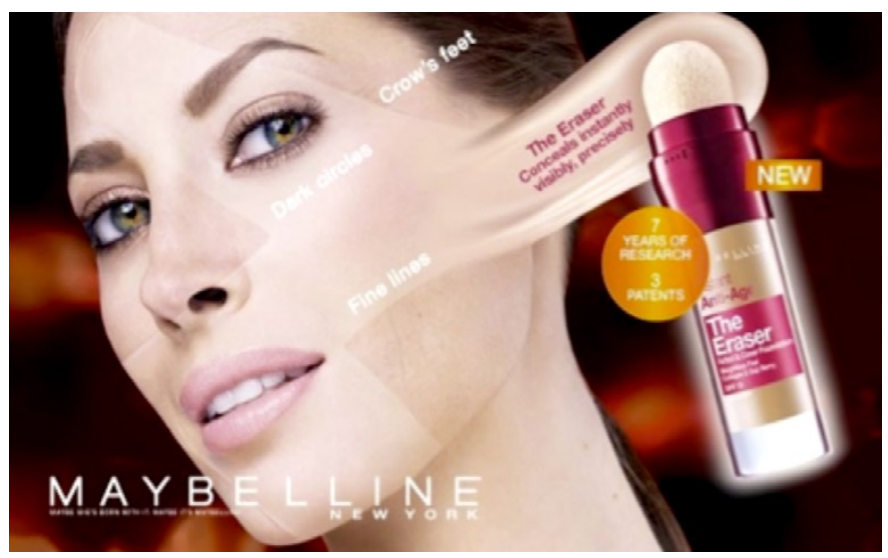

Figura 3

Por último, los mensajes publicitarios en los que el código verbal tiene un papel predominante, a excepción de los publirreportajes, se caracterizan por la economía expresiva y, en consecuencia, las estrategias divulgativas utilizadas, en la mayoría de ocasiones, se centran en destacar los beneficios del producto, desde un punto de vista emocional o social, con el objetivo de llamar la atención del consumidor, mediante el impacto visual y la espectacularidad del componente verbal.

Además, tanto la brevedad como la finalidad persuasiva de los textos publicitarios da lugar a una novedosa estrategia divulgativa centrada en el mantenimiento, e incluso, en la construcción, esencialmente mediante la prefijación, de complejos términos de origen científico que el receptor medio desconoce, con el objetivo de transmitir una imagen de prestigio y calidad con respecto al producto anunciado.

Es el caso de la figura 4, que, en aras de conectar con uno de los tópicos ${ }^{1}$ publicitarios más habituales, esto es, la posibilidad de retrasar el envejecimiento,

1. «Els topoi són principis generals que serveixen de suport al raonament, regles d'inferència gradual que, en ser aplicades a determinats elements del discurs, en provoquen l'orientació argumentativa» (Peraire, 2012: 63). 
combina el componente icónico, que refleja el deterioro de la piel, con un componente verbal breve, basado en el término científico «Tecnología ProGen», cuyo objetivo se centra en ofrecer una imagen de prestigio con respecto a las propiedades del producto anunciado.

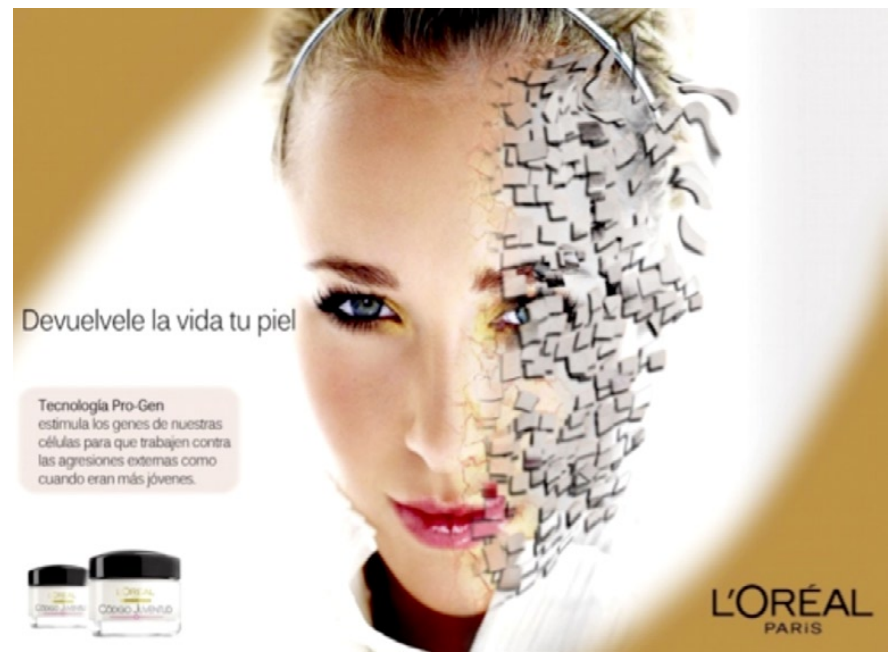

Figura 4

Los géneros audiovisuales, que comprenden, tanto los spots televisivos como los formatos publicitarios de carácter audiovisual que podemos encontrar en Internet ( preroll, ${ }^{2}$ branded content, ${ }^{3}$ etc.), combinan diferentes códigos semióticos como la imagen en movimiento, la música y el sonido, $\mathrm{y}$, por tanto, a pesar de que, concretamente en el caso de los anuncios televisivos, cuentan con limitaciones en cuanto al tiempo de exposición permitido, lo cierto es que este tipo de soportes ofrece la posibilidad de poner en marcha diversas estrategias divulgativas, que, mediante la interacción de diversos sistemas semióticos,

2. Anuncio que aparece antes del visionado de un vídeo en Youtube.

3. Formato publicitario innovador que adopta la estructura de diferentes géneros audiovisuales (series, programas de cocina, eventos, etc.) y que trata de transmitir los valores asociados a la marca, a través de contenidos que despiertan el interés del público objetivo, pero sin destacar los beneficios del producto, que desempeña un papel muy discreto en la trama. 
consiguen potenciar la accesibilidad del mensaje y, en consecuencia, alcanzar el objetivo principal de todo texto publicitario: provocar el acto de compra.

Es el caso de la figura 5, que combina de forma ingeniosa varios sistemas semióticos, entre los que destaca especialmente la música. La letra de la canción seleccionada («Don’t stop me now», del grupo inglés Queen) guarda una estrecha relación con las diferentes escenas del anuncio, que muestran momentos felices de la vida cotidiana, que pueden verse afectados y, en consecuencia, interrumpidos, a causa de un resfriado. El producto, por tanto, se presenta como la solución para evitar que un resfriado común interfiera en la vida cotidiana del consumidor y conecta a la perfección con el universo experiencial del receptor.

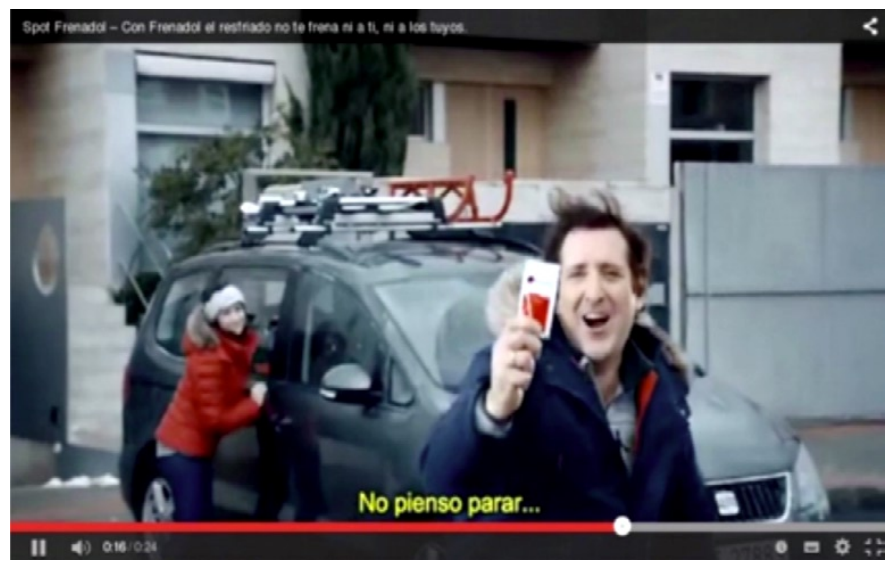

Figura $5^{4}$

b) Recursos divulgativos macrotextuales

Otro de los factores que garantiza la difusión de los contenidos especializados consiste en la adecuación de las estructuras discursivas del texto científico original al modelo discursivo del texto divulgativo.

Los textos publicitarios utilizan diferentes estrategias discursivas, en función del género en el que se inserta el anuncio. Así, es posible encontrar anuncios de productos de origen científico, o seudocientífico, que, con el objetivo

4. https://www.youtube.com/watch?v=3JIkDIUO2c 
de transmitir las ventajas racionales o emocionales del objeto de venta, utilizan diversas modalidades textuales como el diálogo o la narración; recursos estilísticos, especialmente metáforas (visuales o verbales); o elementos modalizadores, como por ejemplo, los testimonios, ya sea de personajes famosos, de expertos en la materia o de consumidores anónimos.

En este sentido resulta interesante analizar aquellos anuncios escritos en los que el componente verbal tiene un papel predominante, ya que presentan algunas diferencias, que dependen del tipo de producto que se desee promocionar. Por un lado, existen mensajes publicitarios que tratan de evocar una falsa sensación de prestigio, a través de la utilización de discursos cargados de terminología de origen científico, ininteligible para la mayoría de los receptores, como la figura 6 , que, además, conecta con el tópico de la eterna juventud. Por otro lado, hay otro tipo de anuncios, como la figura 7, que apelan a los valores, los sentimientos y las creencias del destinatario, mediante la utilización de elementos modalizadores. En este caso, el mensaje trata de asociar, de forma explícitamente subjetiva, el éxito deportivo del futbolista Cristiano Ronaldo, que representa los valores asociados a la marca (salud y culto al cuerpo), con el consumo de los productos HERBALIFE.

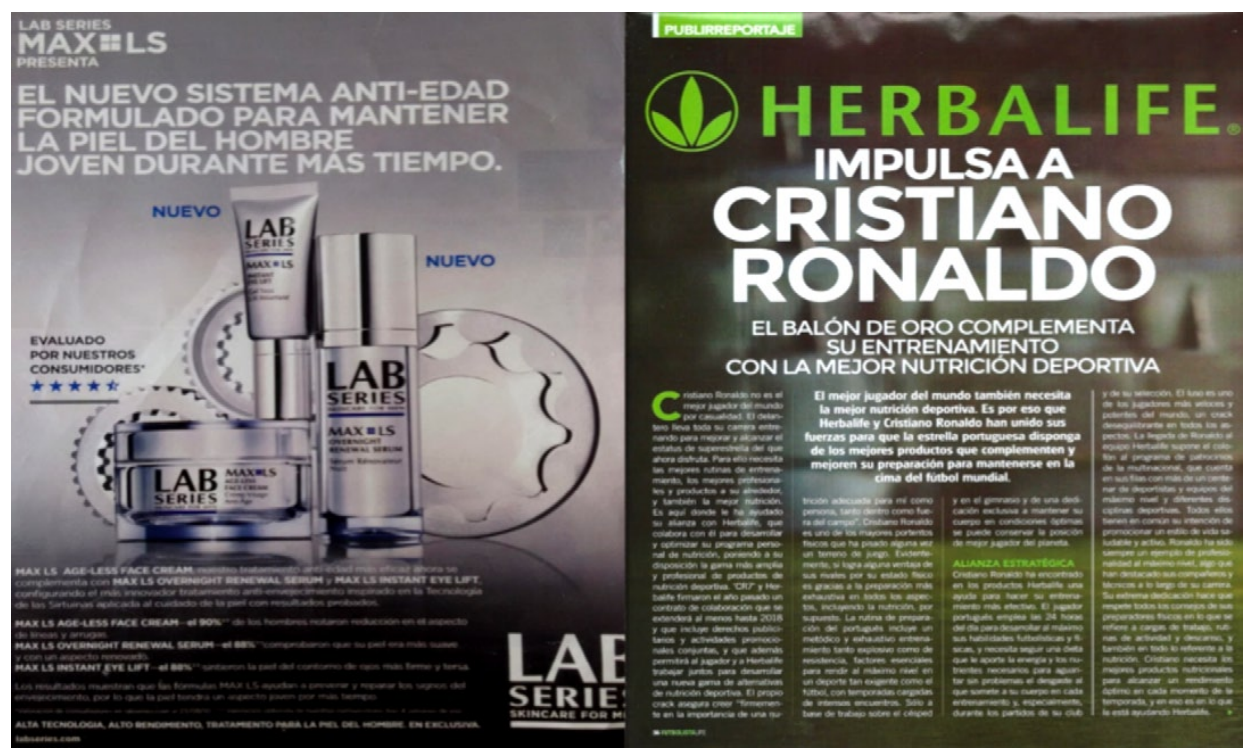

Figura 6

Figura 7 
En cuanto al género publicitario audiovisual, dada la gran variedad de códigos semióticos que lo componen, hay que destacar que incorpora numerosas estrategias discursivas de carácter divulgativo, como por ejemplo, la utilización de la modalidad narrativa. Es el caso de la figura 8, que, en aras de conectar con el tópico de la salud y la higiene, narra una historia, a modo de cuento infantil, que expresa de forma muy didáctica los beneficios del uso diario del producto anunciado.

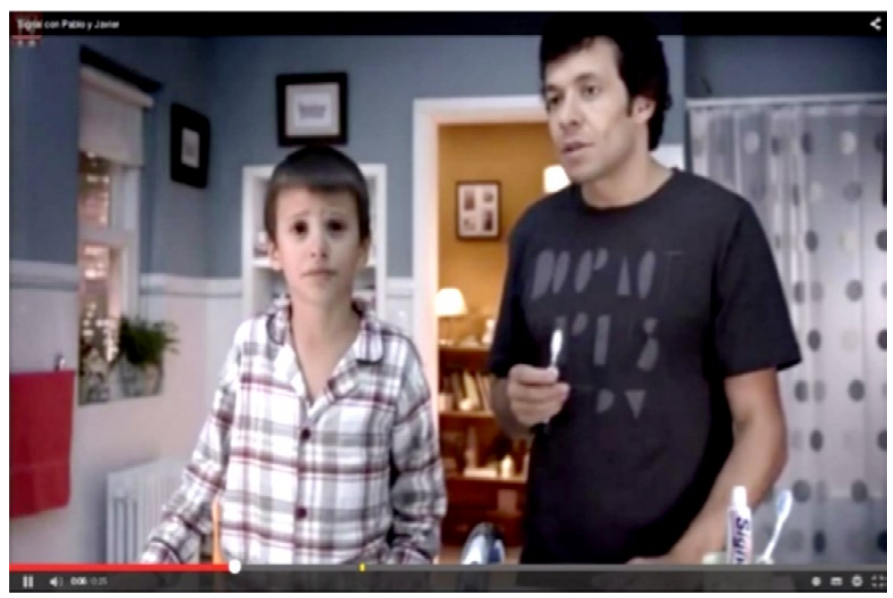

Figura $8^{5}$

\section{RECONCEPTUALIZACIÓN: CLARIFICACIÓN EXPLICATIVA Y CONEXIÓN CON EL UNIVERSO REFERENCIAL DEL RECEPTOR}

El sistema conceptual que envuelve determinados procesos científicos implicados en la producción de algunos productos resulta difícil de comprender para el lector medio. Por ello, los publicitarios desarrollan estrategias discursivas encaminadas a la reconceptualización, es decir, a la clarificación de aquellas nociones, procedentes del ámbito científico, que definen las propiedades del producto anunciado, y que deben adoptar un lenguaje asequible, con el fin de conectar con la experiencia cognitiva del receptor y sus necesidades.

a) En primer lugar, los textos publicitarios de vocación divulgativa, al igual que los textos periodísticos, tratan de explicar, precisar, o matizar,

5. https://www.youtube.com/watch?v=e2yg03pcyuk 
determinados conceptos, que resultan complejos para el lector medio. Para ello, los redactores publicitarios, en el caso de clarificaciones verbales en anuncios escritos, utilizan los incisos oracionales habituales (aposiciones, paréntesis, proposiciones adjetivas, complementos del nombre de tipo preposicional), e incluso, notas a pie de página, tal como podemos observar en la parte inferior izquierda de la figura 9.

Por otra parte, el carácter multimodal de los textos publicitarios hace que el componente icónico adquiera un papel importante en lo que se refiere a la clarificación de determinadas nociones, ya sea mediante la apelación a argumentos de tipo racional, o a los sentimientos y emociones del receptor.

A partir del análisis de la figura 9 , se observa que la imagen ocupa un lugar preponderante en el texto y que el componente verbal rompe la linealidad del discurso, e incluso se mimetiza con el componente icónico, con la finalidad de matizar determinados conceptos, como ocurre con la enumeración de las cinco irregularidades de la piel, incorporadas en el llamativo número 5 , que forma parte del código icónico.

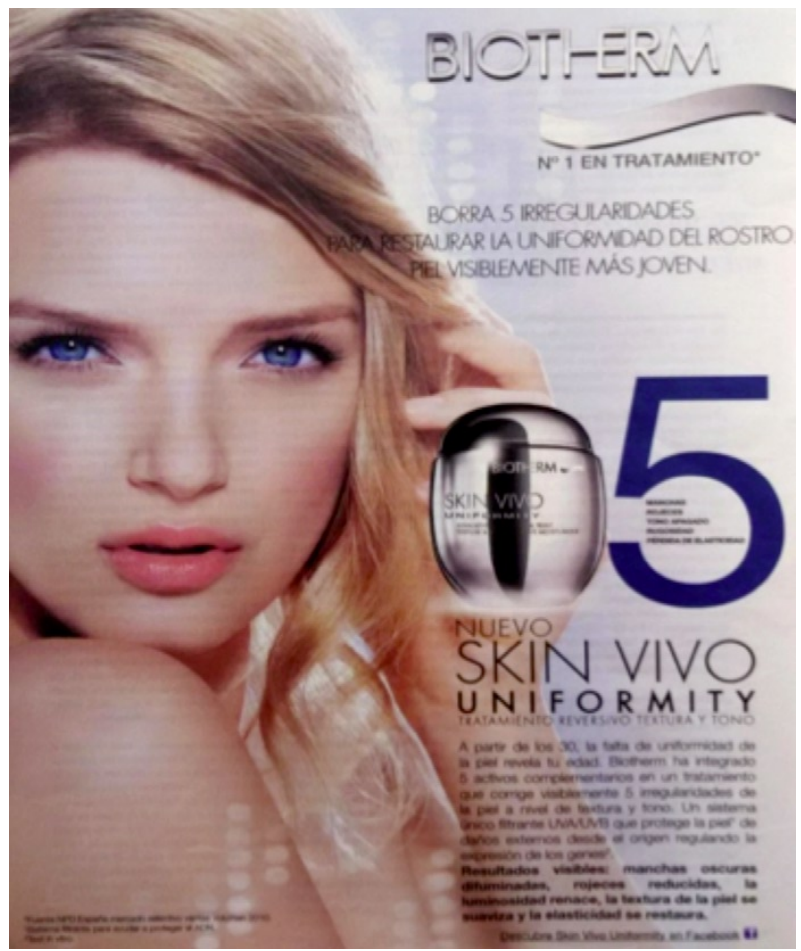

Figura 9 
En lo que se refiere a los soportes audiovisuales, resulta interesante analizar la figura 10, que, con el objetivo de conectar con el tópico de la salud, utiliza la figura del famoso ciclista Miguel Induráin como argumento de autoridad, debido a que este constituye un reflejo del estereotipo social relacionado con un estilo de vida saludable. El mensaje realiza un inciso explicativo, centrado en la forma en que el colesterol impide el flujo normal de la sangre en las arterias, mediante una metáfora visual, que conecta con la experiencia cognitiva del destinatario.

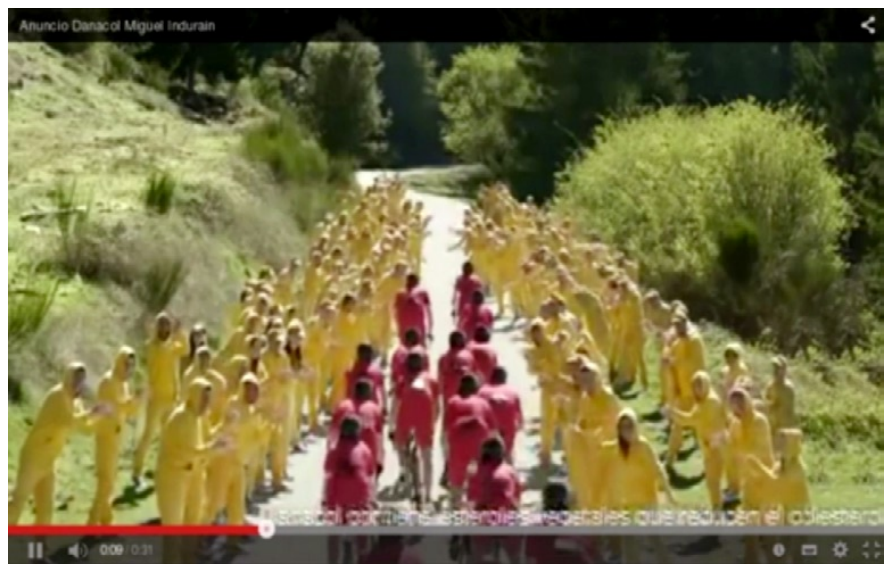

Figura $10^{6}$

b) Otra de las estrategias de reconceptualización de los textos publicitarios tiene su reflejo en los eslóganes y consiste en la simplificación de los mensajes. La simplificación de los complejos conceptos, procedentes del ámbito de la ciencia o de la medicina, que se relacionan con algunos productos, así como su transformación en figuras conocidas por el receptor, se lleva a cabo a través de procedimientos como la metonimia, la metáfora -conceptual u ontológica, ya sea mediante la utilización del código verbal, el icónico o el audiovisual.

Así, son numerosos los eslóganes, tanto en anuncios escritos, como en mensajes publicitarios audiovisuales y digitales, en los que se sigue un modelo metonímico, con el objetivo de explicar un determinado

6. https://www.youtube.com/watch?v=qIQvdpxwVw0 
concepto de origen científico y de establecer una conexión con la vida cotidiana del receptor. Es el caso del famoso eslogan «Barrigas felices» de la marca DANONE, que, con el objetivo de definir, e incluso de atenuar, la expresión relacionada con los beneficios del producto anunciado, utiliza un modelo discursivo metonímico que llega a conferir atribuciones humanas, como el sentimiento de la felicidad, a una parte concreta del cuerpo (la barriga).

La atribución de características humanas a determinados conceptos es un procedimiento discursivo muy habitual en diversos eslóganes publicitarios, que recibe el nombre de metáfora ontológica, y, tal como explican Lakoff y Johnson (1995: 64), constituye diferentes «formas de considerar acontecimientos, actividades, emociones, ideas, etc., como entidades y sustancias», a partir de «nuestras experiencias con objetos físicos (especialmente nuestros propios cuerpos)».

Otra de las estrategias de reconceptualización centrada en la simplificación textual, más habitual, en este caso, en los anuncios televisivos, consiste en la utilización de una metáfora visual para representar un concepto de origen científico, como por ejemplo, las bacterias que causan las caries, encarnadas por los simpáticos dibujos animados que aparecen en el cierre del spot de SIGNAL, que ya ha sido comentado con anterioridad (figura 8).

c) Además de la explicación conceptual, otra de las estrategias discursivas de reconceptualización consiste en señalar los beneficios del consumo del producto para la vida cotidiana del receptor.

Los anuncios de cosméticos constituyen un claro ejemplo de esta estrategia de reconceptualización, ya que, en algunos casos, las propiedades de estos productos carecen de rigor científico y, por tanto, la alternativa del publicitario consiste en centrarse en aspectos puramente emocionales, como la asociación del producto a determinados valores o estereotipos sociales.

Es el caso de la figura 11, que carece de texto verbal, y, en consecuencia utiliza el código icónico, compuesto por la imagen de una joven modelo, para reflejar los resultados que desean las consumidoras de este tipo de productos, y para establecer una asociación entre el producto anunciado y los anhelados estereotipos sociales de la belleza y la juventud, que entroncan con los topois del hedonismo y la juventud eterna. 


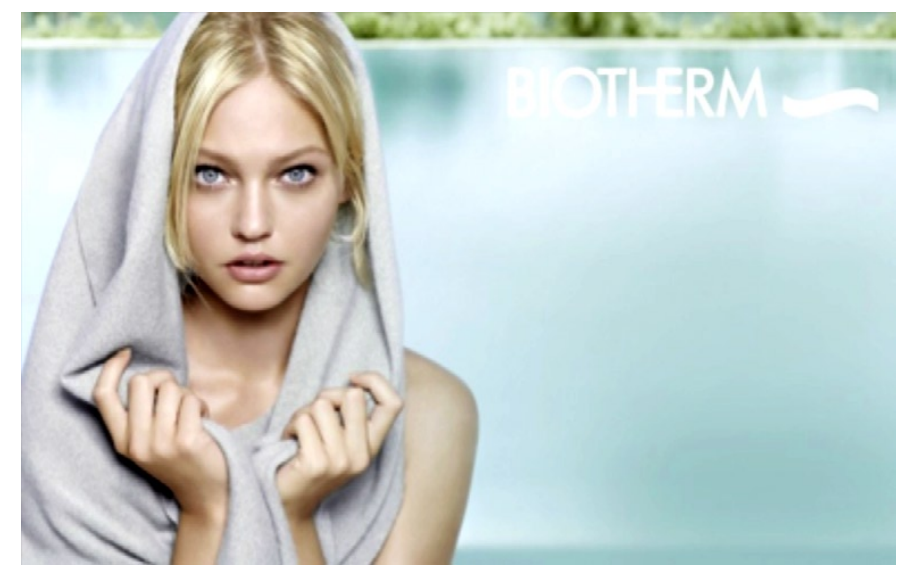

Figura 11

Por otra parte, resulta interesante mencionar que en aquellos anuncios escritos que tratan de convencer al receptor a través de la argumentación verbal, concretamente, en el caso de los anuncios de cosméticos, es muy frecuente encontrar abundante terminología científica, resultados estadísticos acerca de la efectividad del producto, obtenidos a partir de una muestra representativa, y, también, elementos modalizadores, que suelen envolver los beneficios del artículo en un halo de espectacularidad. Es el caso de la figura 6, que combina los resultados de una encuesta realizada a los consumidores acerca de los beneficios del producto anunciado, con determinados recursos, que remiten a aspectos de tipo emocional, relacionados con las creencias, los valores y los estereotipos sociales vigentes, como la denominación de los productos a partir de términos en lengua inglesa; la utilización de vocablos de origen científico, con el objetivo de transmitir una imagen de prestigio; y la aplicación de elementos modalizadores, que confieren un sentido hiperbólico a los beneficios del producto.

En lo que se refiere a los anuncios televisivos, resulta interesante analizar el modo en que la figura 12 reconceptualiza un síntoma de la gripe o el resfriado común como la congestión nasal, mediante un modelo discursivo que exalta los beneficios del producto anunciado. El mensaje se centra en una metáfora visual accesible al público general, que representa la congestión como un impedimento para relacionarse con el sexo opuesto, que solo puede solucionarse gracias al consumo del 
producto anunciado. Por tanto, en este caso, no se trata tanto de explicar las propiedades médicas del producto anunciado como de demostrar la funcionalidad del producto, mediante la apelación a aspectos de carácter emocional, como el deseo sexual y la necesidad de sentirse aceptado por el sexo opuesto.

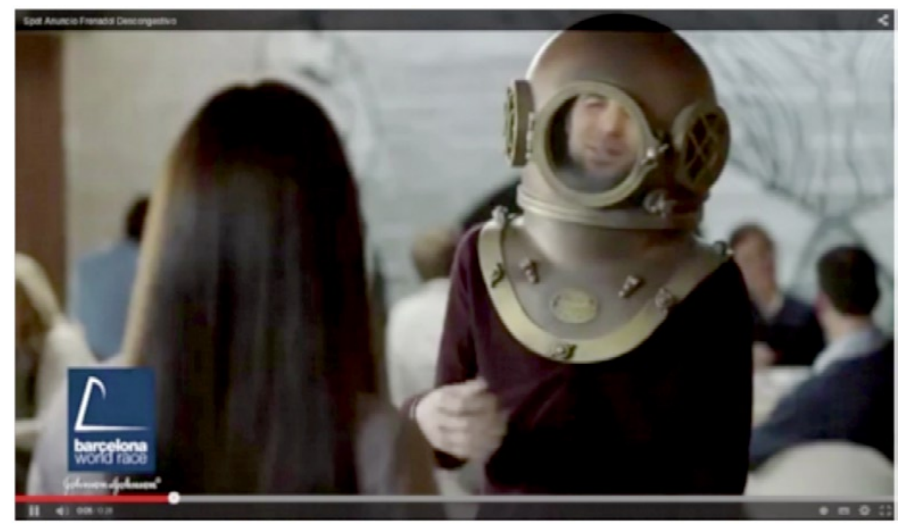

Figura $12^{7}$

d) En cuanto a los mecanismos de cohesión, que orientan la lectura y permiten el acceso a los ejes temáticos, además de los mecanismos reformuladores tradicionales, como los conectores, los procedimientos anafóricos y de recuperación de los contenidos textuales, presentes en los textos publicitarios más extensos (publirreportajes), existe otro tipo de recursos que garantiza un correcto sistema de cohesión discursiva. Un ejemplo de ello es la utilización de la prefijación y, en consecuencia, la creación de nuevos términos, en la mayoría de ocasiones relacionados con el ámbito científico y tecnológico, que, como se comprobará más tarde, además de transmitir una imagen de aparente prestigio, entroncan con los tópicos más característicos del lenguaje publicitario $\mathrm{y}$, en consecuencia, constituyen una parte importante del proceso argumentativo.

7. https://www.youtube.com/watch?v=S0xTqvfbqc 
Por otra parte, también es habitual la utilización de otros recursos cohesivos, como por ejemplo, la nominalización o metáfora gramatical, que, como afirma Salvador (2000: 75), funciona como «una eina de primer ordre per a l'elaboració i la transmissió del coneixement», especialmente en el discuso científico, y, además, se relaciona con la economía expresiva, propia de los textos publicitarios, en los que, en unas ocasiones, reduce un determinado procedimiento o cualidad compleja a un concepto más accesible, y en otras, transmite las connotaciones deseadas (credibilidad, prestigio, innovación, etc.) de forma simplificada.

Los discursos publicitarios de carácter divulgativo, especialmente los anuncios de cosméticos, utilizan este recurso, tanto para explicar las consecuencias de la aplicación del cosmético, mediante el principio de economía expresiva, como para otorgar al producto la imagen de prestigio deseada, como se observa en los siguientes ejemplos: «el suero activador de las proteínas de la juventud» (LANCOME), «la renovación celular» (L'OREAL), «el primer tratamiento de renacimiento capilar» (VICHY NEOGENIC).

e) Otra estrategia de reconceptualización sobre todo en los anuncios en soporte audiovisual, consiste en la coloquialización del mensaje. La finalidad persuasiva de los discursos publicitarios conlleva la utilización de un lenguaje informal, que el receptor identifica como familiar y que, en definitiva, establece una estrecha conexión con su cotidianidad.

La utilización de recursos como la fraseología, expresiones coloquiales, la paremia, diálogos informales, sufijación valorativa, en incluso, canciones populares, es habitual en los mensajes publicitarios, especialmente en los spots, que, en ocasiones, incluso llegan a representar verdaderos relatos. Un ejemplo de ello es la figura 13, que combina las imágenes de personas sufriendo los molestos síntomas de la gripe con una música muy representativa y diversos rótulos en los que se utilizan términos coloquiales, como por ejemplo, trancazo o gripazo. 


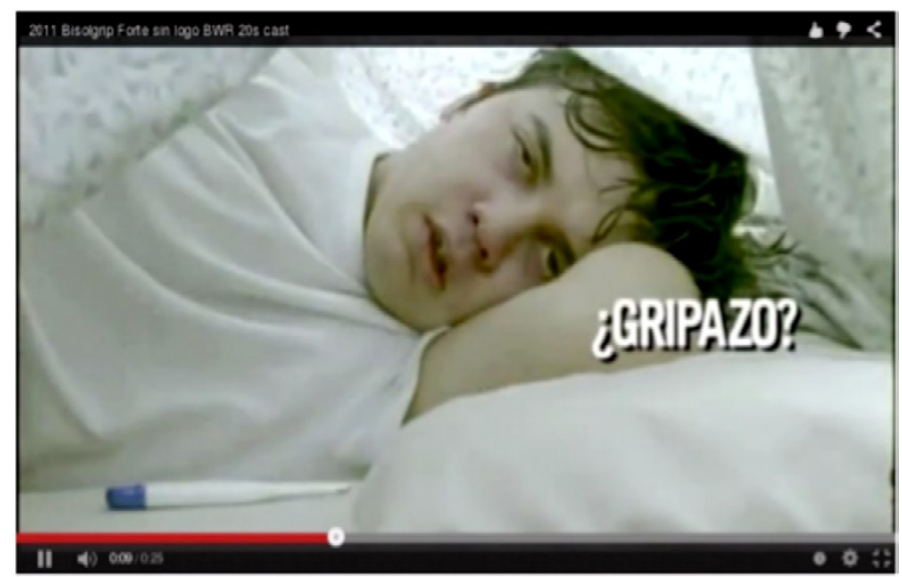

Figura $13^{8}$

\section{REDENOMINACIÓN: IDENTIFICACIÓN LÉXICA Y NEOLOGISMOS DE ORIGEN CIENTÍFICOTECNOLÓGICO (PLASTIC WORDS)}

El papel de la divulgación científica consiste en aplicar estrategias discursivas encaminadas a la redenominación de los complejos términos científicos, con el objetivo de que el receptor identifique las unidades léxicas del mensaje $\mathrm{y}$, en consecuencia, pueda acceder a los conocimientos de origen científico de forma competente.

La creación neológica en los discursos publicitarios, especialmente, en aquellos que forman parte de lo que «se ha dado a llamar pseudocienticismo» (Rodríguez, 2002: 417), esto es, la utilización de terminología de origen especializado para crear una atmósfera ilusoria, de prestigio y credibilidad alrededor de un producto, cuyas propiedades, en algunos casos, carecen de rigor científico, utiliza diferentes estrategias:

a) Uso del lenguaje común.

En los discursos publicitarios, la aproximación de los conceptos de carácter tecnológico o científico al lector medio, en ocasiones, se cen-

8. https://www.youtube.com/watch?v=MkuBwxNI4I 
tra en la utilización de términos accesibles, e incluso, coloquiales, que forman parte del universo referencial del receptor.

Se trata de una estrategia que, habitualmente, se desarrolla, o bien mediante la sustitución del léxico especializado por terminología procedente del lenguaje común, como ocurre en el eslogan «Alimenta tus defensas» (ACTIMEL), que sustituye el conjunto de células, tejidos y órganos que componen el sistema inmunitario por el hiperónimo coloquial defensas; o bien, mediante la aplicación de un modelo discursivo metonímico, como en el caso del eslogan «Corazón sano, corazón contento» (PULEVA OMEGA3), que simplifica los supuestos efectos beneficiosos del producto en lo que se refiere a la prevención de enfermedades cardiovasculares, y, en consecuencia, establece una conexión con la cotidianidad de receptor.

b) Composición y derivación.

La principal estrategia de redenominación en los textos publicitarios consiste en la creación de neologismos a partir de la composición y la derivación. Así, existe un léxico, propiamente publicitario, surgido como resultado de la composición, es decir, de la combinación de dos palabras, como por ejemplo, el vocablo quitagrasas, acuñado por las marcas de productos de limpieza (p. ej., $\mathrm{K}_{H} 7$ ), que ha sustituido en el lenguaje cotidiano al término desengrasante, aceptado por la Real Academia de la Lengua Española.

También existen ejemplos en los que la composición se lleva a cabo «con una palabra abreviada como primer elemento» (Robles y Romero: 2010: 90). Resulta especialmente interesante el caso de términos que surgen a partir de la combinación de la palabra abreviada natur, procedente del término natural, que entronca con el tópico publicitario que asocia la buena salud con la vuelta a lo natural (p. ej., naturfibraCentral Lechera Asturiana).

Además de la composición de palabras, en los textos publicitarios, tal como afirman Robles y Romero (2010: 90), «la neología morfológica se refleja de manera especial en las palabras derivadas, tanto mediante prefijos, como a través de sufijos», debido a que estos elementos léxicos aportan los efectos connotativos necesarios para orientar el proceso argumentativo.

En este sentido, destaca especialmente el papel que desempeña la prefijación, ya que no solo se trata del proceso de creación neológica más habitual en publicidad, sino que además, tal como afirma Vellón (2012: 101), constituye «una estrategia de la persuasión publicitaria», debido 
a que, por un lado, en aquellos anuncios escritos en los que prima el componente icónico, actúa como reclamo visual, se mimetiza con la imagen, e incluso, dirige el itinerario de lectura. Por otro lado, activa los tópicos, o los marcos cognitivos, ${ }^{9}$ que remiten al «mapa cultural» (Rey, 2004: 76) del receptor y dirige el discurso hacia las conclusiones deseadas por el redactor publicitario, con la finalidad de desencadenar el acto de compra.

Los prefijos en publicidad añaden un valor connotativo al término base, que conecta con los tópicos publicitarios más habituales, como por ejemplo, la belleza, el culto al cuerpo y la búsqueda de la eterna juventud. Así, por ejemplo, en anuncios de cosméticos, es interesante mencionar la utilización de términos derivados con el prefijo anti('oposición' y 'prevención'), que no solo conecta con la actual cultura hedonista, sino que además ha creado vocablos, que han irrumpido con tanta fuerza en la lengua común, que finalmente han sido aceptados por la RAE, como por ejemplo, el adjetivo antiarrugas.

c) Creación de plastic words.

La mención de las connotaciones de prestigio e innovación que tratan de transmitir algunos términos conduce irremediablemente al análisis de un grupo específico de prefijos, de origen científico, que actúan como elementos formantes de las llamadas plastic words, que Rodríguez (2002: 418, cfr. Poerksen, 1988) define como «un tipo de palabras, generadas a partir de la combinación del lenguaje científico y el lenguaje común, en las que la connotación es más importante que el significado», es decir, «importa más el halo de prestigio que sugieren que su propio contenido». Se trata de términos neológicos, que además, en su afán de transmitir una sensación de prestigio, incorporan numerosos anglicismos, que surgen a partir de términos científicos reales, a los que se les otorga una función $y$, en consecuencia, un significado diferente.

Este tipo de palabras, compuestas de forma artificial, se relacionan con términos creados por el universo publicitario, como el famoso omega3, que, a pesar de que se corresponde con un concepto científico real, se utiliza en anuncios de productos alimenticios funcionales, especialmente en el caso de la leche enriquecida, con una finalidad muy diferente. En este caso, lo que realmente importa no es el significado real del término, sino su connotación, ya que la presencia del término

9. «Estructuras mentales que conforman nuestro modo de ver el mundo» (Lakoff, 2007: 11). 
omega3 conduce al receptor a establecer una asociación entre el producto y los tópicos presentes en el imaginario colectivo, relacionados con la salud y el bienestar.

A pesar de que las plastic words pueden ser sustantivos simples, derivados o compuestos, lo cierto es que este tipo de términos «destacan por su vitalidad para la derivación» (Rodríguez, 2002: 418, cfr. Poerksen, 1988); en concreto, la prefijación es una de las estrategias más recurrentes para la formación de «palabras ameba» (Rodríguez, 2002: 417) en el universo publicitario. En este sentido, es interesante mencionar el papel que desempeñan los elementos prefijales apreciativos.

Por un lado, entre los prefijos de aumento destacan los de carácter superlativo como extra («extrafina» EVAX), ultra («tecnología ultraglide» NIVEA MEN SENSITIVE) o hiper («hipermejor» HIPERCOR).

Por otro lado, en cuanto a los prefijos de disminución, resulta interesante comentar la presencia del elemento prefijal micro- en la formación de «palabras plásticas» que tratan de transmitir una falsa sensación de prestigio científico acerca de un determinado producto, especialmente en el ámbito de la cosmética. Un ejemplo de ello son las famosas «micropartículas», que aparecen en anuncios de diversas marcas de cosméticos, como por ejemplo, L'OREAL (línea de productos: MEN EXPERT). En este caso, la utilización del prefijo micro-, que tradicionalmente ha actuado como formante de terminología tecnológica (microonda, microchip, microfilm, etc.), genera un término seudocientífico que, aunque carece de significado, cuenta con un valor connotativo que transmite al receptor la idea de que se encuentra ante un producto innovador y efectivo.

d) Uso de anglicismos.

El uso de expresiones foráneas, especialmente de terminología anglosajona, se ha convertido en una característica del discurso publicitario. Esto se debe, por un lado, a que este tipo de términos especializados, aunque en ocasiones resultan ininteligibles para el destinatario, ofrecen una sensación de innovación, prestigio, elegancia y fiabilidad; y, por otro lado, a que «la globalización del mercado, la concentración de la producción y distribución en grandes empresas multinacionales también han favorecido una textualidad que propicia la interacción entre códigos» (Vellón, 2009: 162).

El componente verbal en los anuncios publicitarios, especialmente en los productos que tratan de transmitir un halo de prestigio, suele incorporar extranjerismos, que, en primer lugar, actúan como un reclamo 
visual y un elemento orientador del itinerario de lectura; $y$, en segundo lugar, a causa de su valor connotativo, aportan el eje argumental del mensaje, que, en algunos casos, es desarrollado en lengua española por el resto del componente verbal, mediante estructuras discursivas más amplias, compuestas por diversas modalidades textuales. Un ejemplo de ello es la figura 6, que incorpora terminología inglesa (p .ej., AgeLess Face Cream), cuyo significado se desarrolla posteriormente en lengua española, mediante la modalidad informativo-expositiva.

\section{CONCLUSIÓN}

Las estrategias divulgativas en textos publicitarios de carácter científico o seudocientífico cuentan con una serie de características que las diferencian de los textos divulgativos, pertenecientes a otros géneros textuales como el periodístico, los manuales académicos o los ensayos científicos.

El carácter explícitamente persuasivo del discurso publicitario, junto con sus particulares características, entre las que destacan la multimodalidad y la economía expresiva, convierte la divulgación en un mecanismo argumentativo, que forma parte de estrategia de la persuasión publicitaria, esto es, un recurso que orienta la argumentación discursiva, en aras de alcanzar el efecto perlocucionario que persiguen este tipo de textos: la modificación de la conducta del receptor del mensaje para que se convierta en consumidor del producto anunciado.

\section{REFERENCIAS BIBLIOGRÁFICAS}

Cassany, D.; C. López; J. Martí (2000): «Divulgación del discurso científico: la transformación de redes conceptuales. Hipótesis, modelos y estrategias», Discurso y sociedad, 2: 73103 .

Díaz RoJo, J. A. (2003): «Lenguaje y reclamos de salud en la publicidad de los alimentos», Anàlisi, 30: 217224.

Fuentes, C.; E. AlCaide (2007): La argumentación lingüistica y sus medios de expresión, Madrid, Arco.

Lakoff, G.; M. Johnson (1995): Metáforas de la vida cotidiana, Madrid, Cátedra.

LAKoff, G. (2007): No pienses en un elefante: lenguaje y debate político, Madrid, Complutense. 
Peraire, J. (2012): «L'argumentació publicitària: les paraules del desig», Articles de didàctica de llengua i literatura, 58: 5770.

REY, J. (2004): «Retórica y consumo. Una propuesta metodológica», Questiones Publicitarias: revista internacional de comunicación y publicidad, 1(9): 6583.

Robles, S.; M. V. Romero (2010): Publicidad y lengua española. Un estudio por sectores, SevillaZamora, Comunicación Social. Ediciones y Publicaciones.

Rodríguez, M. A. (2002): «Los prefijos apreciativos como formantes de plastic words», Anuario de Estudios Filológicos, 25: 417432.

Salvador, V. (2000): «L'estil nominalitzat», Caplletra, 29: 6881.

Vellón, J. (2009): «El uso del inglés como estrategia discursiva en el texto publicitario», Cultura, lenguaje y representación, 7: 157182.

- (2012): «La prefijación como estrategia de la persuasión publicitaria: de la neología a la argumentación», Pensar la publicidad, 6(1): 101113.

- (2014): «Divulgación y didacticidad en el discurso periodístico: la información económica durante la crisis», Zer, 19(36): 99119. 